\title{
A COMPARISON OF THE ACCURACY OF THE DETERMINATION OF RIGHT ASCENSION BY MEANS OF TRANSIT INSTRUMENTS OF DIFFERENT TYPES
}

S.P. Izmailov, N.G. Litkevich, S.N. Sadzakov, V.D. Simonenko, T.I. Suchkova, S.A. Tolchelnikova-MurRI, V.I. TURenKo

Kharkov State University Observatory 310022 Kharkov, USSR

ABSTRACT. A special series of observations of the groups of stars performed in Pulkovo, Chile, Kharkov and Belgrade were used to compare the mean errors of the right ascension by means of the method eliminating the influence of the errors of the source catalogue. The results show the advantage of the small transit instruments over transit circles of the classical type.

INDIVIDUAL STAR CATALOGUES OF THE UNIFIED TIME SERVICE OF KHARKOV SCIENTIFIC AND RESEARCH INSTITUTE AND KHARKOV UNIVERSITY ASTRONOMICAL OBSERVATORY

\author{
S.P. Izmailov, N.G. Litkevich, V.D. Simonenko and V.I. Turenko \\ Kharkov State University Observatory \\ 310022 Kharkov, USSR
}

ABSTRACT. The Time Service Catalogue (TSC), which is obligatory for use in all USSR Time Services, was created for the epoch 1958 in the 1970s. Research done in the succeeding years detected a seasonal variation of TSC errors. Thus, a new Time Service Catalogue (TSC2) was required, in order to remove the seasonal errors as well as to satisfy the increasing demands for accuracy in the determination of universal time. During 1986-88 the data of Kharkov Common Time Service for 1980-1987 were reanalyzed using the new system of astronomical constants and two new catalogues were produced.

THE KHARKOV RIGHT ASCENSION CATALOG OF DOUBLE STARS AND HIGH LUMINOSITY STARS FOR THE DECLINATION ZONE $+30^{\circ} \mathrm{TO}+90^{\circ}$

V.M. KIRPATOVSKIJ

Kharkov State University Observatory

310022 Kharkov, USSR

Paper not available. 